\title{
Risk factors for urinary retention after hip or knee replacement: a cohort study
}

\section{Facteurs de risque de rétention urinaire après une arthroplastie de la hanche ou du genou: une étude de cohorte}

\author{
Donald E. G. Griesdale, MD · Jeremy Neufeld, MD • Dale Dhillon, MD • \\ Jennifer Joo, MD · Supna Sandhu, MD • Frank Swinton, MB BCh • \\ Peter T. Choi, MD
}

Received: 6 April 2011/ Accepted: 14 September 2011/Published online: 12 October 2011

(C) The Author(s) 2011. This article is published with open access at Springerlink.com

\begin{abstract}
Introduction In 2006, our provincial government initiated a program to reduce wait times for total hip or knee replacements by referring patients to a single tertiary-care centre. This program provided an opportunity to identify risk factors for perioperative complications as part of a continuing quality improvement project. We report the risk of postoperative urinary retention after hip and knee
\end{abstract}

D. E. G. Griesdale, MD · J. Joo, MD - F. Swinton, MB BCh

P. T. Choi, MD (ه)

Department of Anesthesiology, Pharmacology and Therapeutics, University of British Columbia, 3300 - 910 Tenth Avenue West,

Vancouver, BC V5Z 4E3, Canada

e-mail: PeterT.Choi@vch.ca

S. Sandhu, MD

Department of Medicine, University of British Columbia,

Vancouver, BC, Canada

D. E. G. Griesdale, MD - P. T. Choi, MD

Vancouver Coastal Health Research Institute,

University of British Columbia, Vancouver, BC, Canada

D. E. G. Griesdale, MD - P. T. Choi, MD

Department of Anesthesia, Vancouver Acute, Vancouver,

BC, Canada

F. Swinton, MB BCh

Department of Anesthesia, University Hospital of Northern

British Columbia, Prince George, BC, Canada

J. Neufeld, MD

Department of Anesthesiology, University of Ottawa, Ottawa,

ON, Canada

D. Dhillon, MD

Department of Family Medicine, University of Alberta,

Edmonton, AB, Canada replacements and the risk factors associated with this complication.

Methods After local Research Ethics Board approval, data were abstracted from charts of patients who underwent elective primary unilateral total hip or knee replacement surgery. The outcome was urinary retention in the first $24 \mathrm{hr}$ after surgery. Risk factors were identified using multivariable logistic regression, and they were expressed as odds ratios (OR) or 95\% confidence intervals (CI).

Results From April 1, 2006 to May 31, 2007, 1,440 patients underwent 1,515 elective total hip replacement or total knee replacement. We abstracted data from 1,031 $(71.3 \%)$ patients: mean age, $62 \mathrm{yr}$ (interquartile range [IQR] 55-70); 53.7\% female; 605 total hip replacements; and 426 total knee replacements. The procedures were performed under spinal (81.8\%), general (10.2\%), or combined spinal and general (8.0\%) anesthesia. Patients spent 100 [IQR 90-114] min in the operating room and 3 [IQR 3-4] days in hospital. The 24-hr incidence of urinary retention was $43.3 \%$ (446/1031). Male sex (odds ratio [OR] 3.9; 95\% CI 3.0 to 5.2), total hip replacement (OR 1.4; 95\% CI 1.1 to 1.9), and intrathecal morphine were risk factors.

Discussion Postoperative urinary retention is a common complication after total hip or total knee replacement, especially amongst men and patients receiving intrathecal morphine.

Résumé

Introduction En 2006, notre gouvernement provincial a lancé un programme afin de réduire les temps d'attente pour les arthroplasties totales de la hanche ou du genou en référant les patients à un seul centre de soins tertiaires. Ce programme a été l'occasion d'identifier les facteurs de 
risque de complications périopératoires dans le cadre d'un projet d'amelioration continue de la qualité. Nous rapportons ici le risque de rétention urinaire postopératoire après une arthroplastie de la hanche ou du genou et les facteurs de risque associés à cette complication.

Méthode Après avoir obtenu l'approbation du comité d'éthique de la recherche local, les données ont été extraites des dossiers des patients ayant subi une arthroplastie totale unilatérale primaire et non urgente de la hanche ou du genou. Le critère d'évaluation était la rétention urinaire au cours des 24 premières heures postopératoires. Les facteurs de risque ont été identifiés à l'aide d'une analyse par régression logistique multivariée et ont été exprimés en rapports de cotes [RC] (intervalles de confiance [IC] $95 \%$ ).

Résultats Entre le $1^{\text {er }}$ avril 2006 et le 31 mai 2007, 1440 patients ont subi 1515 arthroplasties totales non urgentes de la hanche ou du genou. Nous avons extrait les données de 1031 (71,3\%) patients [âge 62 ans (écart interquartile [EIQ] 55-70); 53,7\% de femmes; 605 arthroplasties totales de la hanche, 426 arthroplasties totales du genou]. Les interventions ont été réalisées sous rachianesthésie (81,8\%), anesthésie générale (10,2\%), ou rachianesthésie et anesthésie générale combinées $(8,0 \%)$. Les patients ont passé 100 (EIQ 90-114) min en salle d'opération et 3 (EIQ 3-4) jours à l'hôpital. L'incidence à 24 h de rétention urinaire était de 43,3\% (446/1031). Le sexe masculin (rapport de cotes [RC] 3,9; IC 95\% 3,0 à 5,2), l'arthroplastie totale de la hanche (RC 1,4, IC $95 \%$ 1,1 à 1,9) et la morphine intrathécale ont constitué des facteurs de risque.

Discussion La rétention urinaire postopératoire est une complication courante après une arthroplastie totale de la hanche ou du genou, particulièrement chez les hommes et les patients recevant de la morphine intrathécale.

Hip and knee arthroplasties are increasingly common procedures with 62,196 procedures performed in Canada (excluding Quebec) from 2006 to 2007. This total is a $101 \%$ increase over the prior decade and a $6 \%$ increase over the prior year. ${ }^{1}$ Spinal anesthesia is a common choice of anesthesia for these procedures, ${ }^{\mathrm{A}}$ which are often performed on elderly patients with comorbid conditions.

The risk for urinary retention after hip or knee arthroplasty has varied widely amongst different reports depending on the anesthesia and analgesia with estimates ranging from 0 to $75 \%{ }^{2}$ In one recent review, the authors estimated the pooled weighted mean incidence to be as low

\footnotetext{
A Available at http://www.postoppain.org/content.aspx?nid=57632 and http://www.postoppain.org/image.aspx?imgid=654 (Both accessed 24 March 2010).
}

as $8.8 \%$ (95\% confidence interval [CI] 5.2 to 12.4) for continuous peripheral nerve blockade to as high as $34.1 \%$ (95\% CI 32.9 to 35.4 ) for epidural analgesia. ${ }^{2}$ Postoperative urinary retention can lead to significant morbidity, such as prosthetic infection and sepsis. ${ }^{2}$ Urinary retention following spinal anesthesia for hip or knee arthroplasty is well documented, but estimates of risks are based on small samples and vary widely amongst reports. ${ }^{2}$ Similarly, identification of risk factors for urinary retention in this population has resulted in discrepant conclusions. ${ }^{2}$

The opening of the Centre for Surgical Innovation (CSI), an initiative to reduce wait times for hip and knee arthroplasties in the province of British Columbia (BC), Canada, provided us the opportunity to study a large homogeneous group of patients who underwent hip or knee arthroplasties under similar anesthetics. The purposes of this study were to estimate the 24-hr risk of postoperative urinary retention in a cohort of patients undergoing primary elective unilateral total hip or total knee arthroplasty and to identify risk factors for postoperative urinary retention in the same cohort.

\section{Methods}

This article on our single-centre cohort study is reported in accordance with the STrengthening the Reporting of OBservational studies in Epidemiology (STROBE) guidelines. $^{3,4}$

Study setting and participants

In February 2006, the BC provincial government and the Vancouver Coastal Health Authority established the University of BC Hospital (Vancouver Acute) Centre for Surgical Innovation (CSI) and implemented the Osteoarthritis Service Integration System (OASIS) Program to reduce the wait times for elective major joint reconstructive surgery. The University of BC Hospital is a tertiary-referral centre in Vancouver, BC affiliated with the University of BC. The CSI focuses on elective primary total hip and knee replacement procedures. Patients requiring joint replacement from acute trauma, such as hip fractures, are ineligible. Participating orthopedic surgeons from all over the province identify and schedule eligible patients for surgery at the Centre. To avoid delays and cancellations, all CSI patients are evaluated at the Vancouver Acute anesthesia consult clinic at least $24 \mathrm{hr}$ prior to surgery. The first hip and knee replacement procedures were performed on April 1, 2006.

Although the anesthetics were not standardized, they were similar amongst the members of the department. For general anesthesia, induction was achieved with 
intravenous fentanyl, propofol, and rocuronium. Anesthesia was maintained using sevoflurane or desflurane with rocuronium and long-acting intravenous opioids (morphine or hydromorphone) administered as needed. In some cases, an intravenous propofol infusion was added. For spinal anesthesia, neuraxial blockade was achieved using intrathecal long-acting local anesthetic (bupivacaine or ropivacaine) with intrathecal morphine added at the discretion of the attending anesthesiologist. All patients received cefazolin $2 \mathrm{~g}$ iv (or clindamycin $600 \mathrm{mg}$ iv if penicillin allergy was documented) prior to surgical incision. Intravenous fluid therapy consisted of crystalloids (normal saline or Plasmalyte) only. All patients received oral oxycodone and patient-controlled analgesia with intravenous morphine or hydromorphone in the postoperative period. Physiotherapy and nursing care followed a clinical pathway to promote consistency of care. With regard to voiding, the nursing policy was to avoid routine intraoperative or postoperative catheterization of the patient's bladder due to concerns of infection.

As this was a retrospective study using patient records, the UBC Clinical Research Ethics Board waived the requirement for informed consent when it granted approval. After approval for access of information from the Vancouver Coastal Health Authority, hospital records of patients who were admitted to the CSI for primary hip or knee unilateral replacement procedures from April 1, 2006 to May 31, 2007 were identified through the Operating Room Management Information System (ORMIS) using the Vancouver Coastal Health procedure codes for primary hip and knee replacement procedures. Patients were included in this study if they met the Centre's admission criteria: age 14 to $80 \mathrm{yr}$, American Society of Anesthesiologists' (ASA) physical status class I-III, body mass index $<40 \mathrm{~kg} \cdot \mathrm{m}^{-2}$, pre-assessment $24-\mathrm{hr}$ opiate consumption $\leq 60 \mathrm{mg}$ oral morphine, consent given to receive blood transfusions, and absence of coagulation disorders or obstructive sleep apnea-hypopnea (based on overnight oximetry or polysomnography). Patients were excluded from this study if they had a history of chronic urinary retention (e.g., neurogenic bladder); they were admitted to the CSI but did not receive an anesthetic and undergo surgery (i.e., cancellation of case), or they received an indwelling bladder catheter intraoperatively. For patients who underwent more than one operation (on separate admissions) at the CSI, we used the data from the first admission only.

As we did not have a prior estimate of the rate of urinary retention in the population of interest at our Centre, our initial plan was to sample all eligible patients. After abstracting data from the records of 100 patients, we determined that all eligible patients were not necessary to achieve an adequate sample size (see below), and a random sample was chosen to save time and money. The order in which the paper records were sampled was randomized by the Health Record staff who held the master list of all eligible patients.

We abstracted data from individual patient paper records and entered our data directly into a Microsoft Excel ${ }^{\mathrm{TM}}$ spreadsheet. The spreadsheet included a data dictionary defining each variable and a guide to the source document where the variable could be located in the hospital record. To ensure consistency, each data abstractor (J.N., D.D., J.J.) underwent a training period wherein they and the senior investigator (P.T.C.) abstracted data independently from at least ten health records. When each data abstractor achieved $100 \%$ agreement with the senior investigator, s/he proceeded to abstract data independently. In addition, we conducted weekly internal consistency checks of the data tables to flag potential discrepancies or errors (e.g., coding "yes" for intrathecal morphine and coding " $0 \mu \mathrm{g}$ " for its dose) during the data collection period.

Variables

We abstracted data on variables related to demographics, comorbid conditions, preoperative medications, surgical and anesthetic details, surgical and anesthetic staff, times, and postoperative complications (including nausea, vomiting, pruritis, urinary retention in the first $24 \mathrm{hr}$ after surgery, and postoperative pain during hospital admission). Values for variables derived from other variables (e.g., body mass index, durations) were calculated using formulae in the spreadsheet. Opioid dosages were recorded as equivalents in milligrams of morphine for each route of administration.

\section{Study outcome}

The outcome for this analysis was urinary retention in the first $24 \mathrm{hr}$ after surgery. The diagnostic criterion for urinary retention was postoperative urinary (intermittent or indwelling) catheterization due to 1) documented symptoms related to an inability to void after surgery or 2) postoperative urinary retention identified by bladder ultrasonography.

\section{Sample size}

Our initial goal was to collect data from all patients meeting our selection criteria in the population of interest. After data had been collected on the first 100 patients, the estimated 24-hr risk of urinary retention was $42 \%$ (95\% CI 32.8 to 52.8 ). The estimated 24 -hr risk of urinary retention was $60 \%(21 / 35 ; 95 \%$ CI 43.6 to 74.5$)$ in men and $32 \%$ (21/65; 95\% CI 22.2 to 44.4$)$ in women. Since the purpose 
of this study was to determine risk factors for urinary retention, we designed our sample size in order to assure stability around point estimates in a multivariable model, even when examining for subgroup effects (e.g., sex). Assuming 30\% risk of urinary retention in females, with twelve covariates to be used in the final multivariable model (including interaction covariates) and using ten covariates per outcome as recommended by Peduzzi et al.,$^{5}$ approximately 400 female patients would be required. Allowing for incomplete outcome and predictor ascertainment, we estimated that 1,000 patients would be sufficient for the number of variables to be included in a multivariable analysis. The precision of the point estimate (based on the $95 \%$ CI half-width) would range from $2.8 \%$ (for an incidence of $30 \%$ ) to $3.1 \%$ (for an incidence of $50 \%$ ) with 1,000 patients.

\section{Statistical analyses}

We used Stata release 10 (StataCorp, TX, USA) to analyze our data. We described categorical data, normally distributed data, and non-normally distributed data using proportions (percent), mean (standard deviation [SD]), and median (interquartile range [IQR]), respectively. Bivariate analysis of categorical and continuous data was performed using Chi square and two-sample Student's $t$ tests, respectively. For the dosage of intrathecal morphine, we collapsed the continuous data into four strata (none, $\leq 100 \mu \mathrm{g}, 101$ to $150 \mu \mathrm{g}$, and $>150 \mu \mathrm{g}$ ). Similarly, we collapsed the data on intrathecal long-acting local anesthetic dosage into four strata (none, $\leq 10 \mathrm{mg}, 10.1$ to $12.5 \mathrm{mg}$, and $>12.5 \mathrm{mg}$ ). Multivariable logistic regression was used to model the association between postoperative urinary retention and independent variables. Independent variables were chosen a priori based on their potential association with the outcome variable reported in prior studies. These variables were: procedure (total hip $v s$ total knee arthroplasty), age (yr), male sex, dose of intrathecal long-acting local anesthetic (as an ordinal variable), and dose of intrathecal long-acting morphine. The dose of longacting intrathecal morphine was inserted as an indicator variable with the referent category being general anesthesia and the indicators being: spinal anesthesia without morphine, $\leq 100 \mu \mathrm{g}, 101$ to $150 \mu \mathrm{g}$, and $>150 \mu \mathrm{g}$. Fractional polynomials were used to ensure the best functional form of the continuous variable "age". Finally, we assessed for effect measure modification of sex by dose of intrathecal morphine by introducing interaction terms into the final model. A complete-case analysis was performed. All tests were two-sided and we considered a $P$ value $<0.05$ level to be statistically significant.

\section{Results}

From April 1, 2006 to May 31, 2007, 1,440 patients underwent 1,515 total hip or total knee arthroplasties. During this period, 1,366 patients, 73 patients, and one patient underwent one, two, and three major lower limb arthroplasties, respectively. By the time all data abstractors were notified that the sample size (1,000 patients) had been reached, we had abstracted data relating to the first procedure performed on 1,031 (71.3\%) randomly sampled subjects of the 1,440 patients. The flow diagram for this study is shown in Fig. 1.

The mean age of the 1,031 patients was $61.8(10.8) \mathrm{yr}$; $477(46.3 \%)$ were men. The preoperative patient characteristics by postoperative urinary status are described in Table 1. Of the 1,031 patients, $605(58.7 \%)$ underwent total hip arthroplasties and $426(41.3 \%)$ underwent total knee arthroplasties. Procedures were performed under spinal anesthesia $(n=844,81.8 \%)$, general anesthesia $(n=105,10.2 \%)$, or combined spinal and general anesthesia $(n=82,8.0 \%)$. Patients spent 100 (IQR [90-114]) $\mathrm{min}$ in the operating room, 128 [96-165] $\mathrm{min}$ in the recovery room, and three [3-4] days in hospital. The

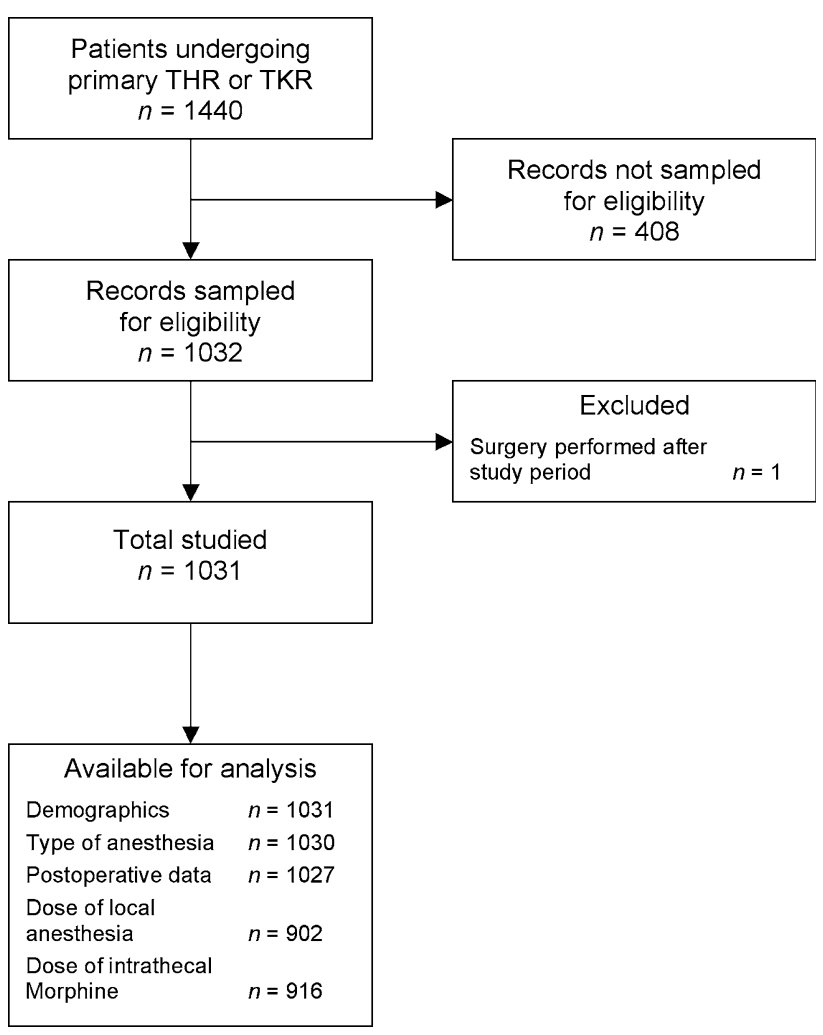

Fig. 1 Flow diagram of subjects studied 
Table 1 Preoperative patient characteristics by status of postoperative urinary retention

\begin{tabular}{|c|c|c|c|}
\hline & $\begin{array}{l}\text { Urinary } \\
\text { retention } \\
(n=446)\end{array}$ & $\begin{array}{l}\text { No urinary } \\
\text { retention } \\
(n=585)\end{array}$ & $P$ value \\
\hline Age (yr), mean (SD) & $61.3(10.5)$ & $62.2(10.7)$ & 0.20 \\
\hline Male sex, $n(\%)$ & $288(64.6)$ & $189(32.3)$ & $<0.001$ \\
\hline $\begin{array}{l}\text { Body mass index }\left(\mathrm{kg} \cdot \mathrm{m}^{-2}\right) \\
\text { mean }(\mathrm{SD})\end{array}$ & $28.8(5.4)$ & $29.3(5.3)$ & 0.14 \\
\hline ASA classification, $n(\%)$ & & & 0.04 \\
\hline I & $84(18.8)$ & $78(13.3)$ & \\
\hline II & 347 (77.8) & 479 (81.9) & \\
\hline III & $15(3.4)$ & $28(4.8)$ & \\
\hline Smoking status, $n(\%)$ & & & 0.90 \\
\hline Non-smoker & 325 (72.9) & $434(74.2)$ & \\
\hline Ex-smoker & $85(19.1)$ & $99(16.9)$ & \\
\hline Current smoker & $36(8.1)$ & $52(8.9)$ & \\
\hline Preoperative opioid use, $n(\%)$ & $45(10.1)$ & $70(12.0)$ & 0.90 \\
\hline $\begin{array}{l}\text { Preoperative beta blocker use, } \\
\quad n(\%)\end{array}$ & $28(6.3)$ & $53(9.1)$ & 0.10 \\
\hline
\end{tabular}

operative and anesthetic characteristics by postoperative urinary status are described in Table 2.

The overall 24-hr risk of postoperative urinary retention was $43.3 \%$ (446/1031; $95 \%$ CI 40.3 to 46.3 ). The risk was $60.4 \%$ (288/477; $95 \%$ CI 55.9 to 64.7$)$ amongst men and $28.5 \%$ (158/554; $95 \%$ CI 24.9 to 32.4 ) amongst women. On bivariate analysis, statistically significant differences (all $P<0.001$ unless noted) were observed for male sex, ASA physical status $(P=0.04)$, type of procedure, type of anesthetic, dose of intrathecal local anesthetic, and dose of intrathecal morphine (Tables 1 and 2). The final unadjusted and adjusted multivariable logistic regression models are presented in Table 3. The final multivariable model included 435 outcome events in 1,006 patients. Both male sex and total hip arthroplasty (compared with total knee arthroplasty) were associated with increased odds of postoperative urinary retention. Compared with general anesthesia alone, any intrathecal morphine administration was associated with increased odds of postoperative urinary retention. We did not identify a dose-response relationship when we examined only those patients who received any intrathecal morphine (test-for-trend $P=0.07)$.

As stated in the previous section, there was effect measure modification on dose of intrathecal morphine by sex (interaction $P<0.001$ ). These results are presented in Fig. 2. For males, there was a strong relationship between presence of intrathecal morphine and the odds of postoperative urinary retention that was not present for females.
Table 2 Operative and anesthetic characteristics by status of postoperative urinary retention

\begin{tabular}{|c|c|c|c|}
\hline & $\begin{array}{l}\text { Urinary } \\
\text { retention } \\
(n=446)\end{array}$ & $\begin{array}{l}\text { No urinary } \\
\text { retention } \\
(n=585)\end{array}$ & $P$ value \\
\hline Procedure, $n(\%)$ & & & $<0.001$ \\
\hline Total knee arthroplasty & $157(35.2)$ & $269(46.0)$ & \\
\hline Total hip arthroplasty & $289(64.8)$ & $316(54.0)$ & \\
\hline $\begin{array}{l}\text { Oral opioid } \\
\quad \text { postoperatively, } n(\%)\end{array}$ & $87(19.5)$ & $104(17.8)$ & 0.40 \\
\hline Type of anesthesia, $n(\%)$ & & & $<0.001$ \\
\hline General anesthesia & $23(5.2)$ & $82(14.2)$ & \\
\hline $\begin{array}{l}\text { General and spinal } \\
\text { anesthesia }\end{array}$ & $41(9.2)$ & $40(6.8)$ & \\
\hline Spinal anesthesia & $382(85.7)$ & $462(79.0)$ & \\
\hline Missing & 0 & $1(0.2)$ & \\
\hline $\begin{array}{l}\text { Intrathecal local } \\
\quad \text { anesthesia* dose, } n(\%)\end{array}$ & & & $<0.001$ \\
\hline General anesthesia only & $23(5.2)$ & $82(14.2)$ & \\
\hline$\leq 10 \mathrm{mg}$ & $94(21.1)$ & $161(27.5)$ & \\
\hline $10.1-12.5 \mathrm{mg}$ & $190(42.6)$ & $224(38.3)$ & \\
\hline$>12.5 \mathrm{mg}$ & $128(28.7)$ & $105(18.0)$ & \\
\hline Missing & $11(2.5)$ & $13(2.2)$ & \\
\hline $\begin{array}{l}\text { Intrathecal morphine } \\
\quad \text { dose, } n(\%)\end{array}$ & & & $<0.001$ \\
\hline General anesthesia only & $23(5.2)$ & $82(14.0)$ & \\
\hline $\begin{array}{l}\text { Spinal anesthesia without } \\
\text { morphine }\end{array}$ & $42(9.4)$ & 109 (18.6) & \\
\hline$\leq 100 \mu \mathrm{g}$ & $253(56.7)$ & $287(49.1)$ & \\
\hline $101-150 \mu \mathrm{g}$ & $89(20.0)$ & $65(11.1)$ & \\
\hline$>150 \mu \mathrm{g}$ & $37(8.3)$ & $34(5.8)$ & \\
\hline Missing & $2(0.5)$ & $8(1.4)$ & \\
\hline $\begin{array}{l}\text { Median minutes in } \\
\text { operating room [IQR] }\end{array}$ & $101[90-115]$ & 100 [90-113] & 0.26 \\
\hline $\begin{array}{l}\text { Median minutes in } \\
\text { recovery room [IQR] }\end{array}$ & $130[98-165]$ & $125[95-165]$ & 0.48 \\
\hline $\begin{array}{l}\text { Median days of hospital } \\
\text { stay [IQR] }\end{array}$ & $3[3-4]$ & $3[3-4]$ & 0.62 \\
\hline
\end{tabular}

* Bupivacaine or ropivacaine; IQR = interquartile range

Compared with general anesthesia alone, males receiving spinal anesthesia with morphine had a 7.1 to 12.2 -fold increased odds of postoperative urinary retention. Once again, we did not see a dose-response relationship (test-fortrend $P=0.13$ ). For both males and females, spinal anesthesia without morphine was not associated with postoperative urinary retention.

\section{Discussion}

In this single tertiary centre cohort study, the 24-hr risk of postoperative urinary retention after elective primary 
Table 3 Multivariable logistic regression analysis of factors that are related to postoperative urinary retention

$\mathrm{CI}=$ confidence interval;

$\mathrm{OR}_{\mathrm{adj}}=$ adjusted odds ratio;

$\mathrm{OR}_{\text {unadj }}=$ unadjusted odds ratio

Fig. 2 Odds ratios of urinary retention by dose of intrathecal morphine and gender

\begin{tabular}{|c|c|c|c|c|}
\hline Variable & $\mathrm{OR}_{\text {unadj }}$ & $\mathrm{OR}_{\mathrm{adj}}$ & $95 \% \mathrm{CI}$ & $P$ value \\
\hline Total hip arthroplasty & 1.6 & 1.4 & 1.1 to 1.9 & 0.02 \\
\hline Age (yr) & 0.99 & 1.0 & 1.0 to 1.0 & 0.85 \\
\hline $\begin{array}{l}\text { Dose of intrathecal long-acting } \\
\text { local anesthetic }\end{array}$ & 1.5 & 1.2 & 0.94 to 1.4 & 0.17 \\
\hline \multicolumn{5}{|l|}{ Type of anesthetic by gender } \\
\hline \multicolumn{5}{|l|}{ Male } \\
\hline General anesthesia only & 1.0 & 1.0 & - & \\
\hline $\begin{array}{l}\text { Spinal anesthesia without } \\
\text { intrathecal morphine }\end{array}$ & 1.5 & 1.6 & 0.71 to 3.6 & 0.26 \\
\hline$\leq 100 \mu \mathrm{g}$ intrathecal morphine & 6.5 & 7.1 & 3.6 to 14.0 & $<0.001$ \\
\hline $101-150 \mu \mathrm{g}$ & 8.6 & 9.3 & 4.2 to 20.1 & $<0.001$ \\
\hline$>150 \mu \mathrm{g}$ & 11.6 & 12.2 & 4.3 to 34.5 & $<0.001$ \\
\hline \multicolumn{5}{|l|}{ Female } \\
\hline General anesthesia only & 1.0 & 1.0 & - & \\
\hline $\begin{array}{l}\text { Spinal anesthesia without } \\
\text { intrathecal morphine }\end{array}$ & 1.3 & 1.3 & 0.59 to 2.9 & 0.51 \\
\hline$\leq 100 \mu \mathrm{g}$ intrathecal morphine & 1.7 & 1.7 & 0.84 to 3.3 & 0.14 \\
\hline $101-150 \mu \mathrm{g}$ & 2.8 & 2.6 & 1.2 to 5.8 & 0.02 \\
\hline$>150 \mu \mathrm{g}$ & 1.5 & 1.4 & 0.53 to 3.6 & 0.51 \\
\hline
\end{tabular}

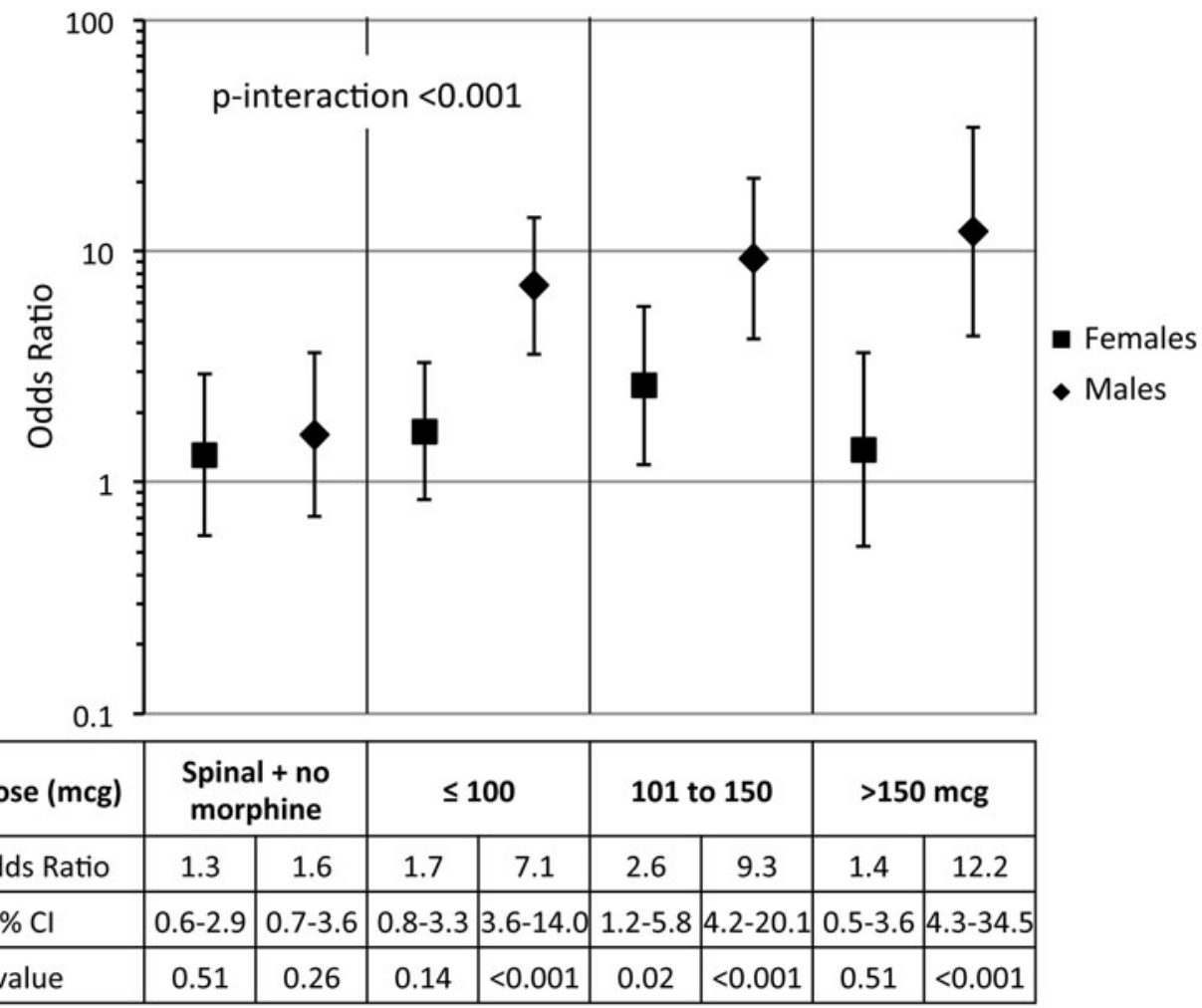

unilateral total hip or total knee arthroplasty was $43.3 \%$ (95\% CI 40.3 to 46.3). Male sex, total hip arthroplasty, and the presence of any dose of intrathecal morphine were associated with this complication. Furthermore, the increased risk of postoperative urinary retention with intrathecal morphine appeared to be confined primarily to males, as evident from significant effect measure modification in our cohort.

Our results are consistent with the results from many prior studies. However, as with all observational studies, 
unmeasured and residual confounding are potential sources of bias in this study. The fast-track nature of the OASIS Program meant that patients at the CSI were relatively young healthy subjects with few comorbid conditions compared with subjects in prior studies. ${ }^{6-10}$ As a result, there may be some selection bias and an underestimate of the risk of urinary retention.

The nurses were unblinded to the anesthetic agents in this study, and there was a potential bias that nurses were more likely to insert a bladder catheter in patients receiving intrathecal morphine, which could overestimate the effect of intrathecal morphine on the risk of urinary retention. However, formal clinical pathways were used during the study period, and the nursing policy was to avoid routine bladder catheterization.

Several studies have found age $>70 \mathrm{yr}$ to be a risk factor for postoperative urinary retention. ${ }^{8,11}$ We did not identify age as a risk factor in our cohort. Our Centre's upper age limit of $80 \mathrm{yr}$ may explain why age was not associated with urinary retention in our study sample. Furthermore, any inference of age must be interpreted with caution as the interquartile range was 55-70 yr.

Prior studies have identified obstructive urological symptoms to be associated with postoperative urinary retention following major lower joint arthroplasty. ${ }^{2}$ Although we excluded patients with a history of chronic urinary retention, we did not exclude patients with benign prostatic hypertrophy. Unlike prospective studies evaluating preoperative urinary tract or prostate symptoms, ${ }^{7,8,12}$ we could not determine a history of obstructive urological symptoms with accuracy due to our reliance on existing records; thus, we did not examine preoperative urological symptoms as a variable in our study. Compared with women, the increased risk of postoperative urinary retention amongst men receiving intrathecal morphine may be related to prostate symptoms.

Similarly, perioperative fluid administration may play a role in the development of postoperative urinary retention by overdistension of the bladder. ${ }^{2}$ As we were unable to abstract accurate data from the patients' medical records regarding the volume of fluids administered, we did not examine the perioperative fluid administration as a variable in our study.

In a very recent cohort study, Hansen et al. found lack of preoperative voiding to be associated with postoperative urinary retention (OR 4.20; 95\% CI 2.46 to 7.16$).{ }^{13}$ Unfortunately, we did not collect this information in our study, and we can neither corroborate nor refute this association.

In spite of potential biases, our study has several strengths. The anesthetic, surgical, and nursing practices at the CSI were very uniform to maximize efficiency and patient flow from hospital admission to hospital discharge. The high volume of the two surgical procedures allowed us to achieve a large sample size in this study.
Our results are generalizable to orthopedic centres that have large volumes of reasonably healthy patients undergoing major lower limb joint arthroplasty. The results may be applicable to older sicker patients undergoing the same procedure but are likely to be an underestimate of the true risk.

Since dissemination of our results within our own centre, we have implemented bladder ultrasonography in the recovery room for earlier diagnosis of this common complication. Even though urinary retention is associated with an increased risk of urinary tract infections and subsequent prosthetic infection, the use of prophylactic indwelling bladder catheters is still debatable as indwelling catheters also increase the risk of urinary tract infections. ${ }^{2}$ Voiding immediately prior to surgery, early diagnosis of urinary retention, and intermittent catheterization may be the best approach. ${ }^{2,13-16}$ Based on our results, individuals who are undergoing total hip arthroplasty or are male will be at an increased risk. For men, this risk is increased in the presence of intrathecal morphine.

Acknowledgements We thank Dr. Penny Brasher for her assistance with the sample size calculation and the personnel in Health Records at the University of British Columbia Hospital for their assistance with the sampling of hospital records.

Financial Support Intramural departmental funds (UBC). Dr. Griesdale is supported by a Mentored Clinician Scientist Award from the VGH and UBC Hospital Foundation.

\section{Conflicts of interest or other associations None declared.}

Open Access This article is distributed under the terms of the Creative Commons Attribution Noncommercial License which permits any noncommercial use, distribution, and reproduction in any medium, provided the original author(s) and source are credited.

\section{References}

1. Canadian Institute for Health Information. Hip and Knee Replacements in Canada-Canadian Joint Replacement Registry (CJRR) 2008-2009 Annual Report. Ottawa: CIHI; 2009

2. Balderi T, Carli F. Urinary retention after total hip and knee arthroplasty. Minerva Anestesiol 2010; 76: 120-30.

3. von Elm E, Altman DG, Egger M, et al. The Strengthening the Reporting of Observational Studies in Epidemiology (STROBE) Statement: guidelines for reporting observational studies. Ann Intern Med 2007; 147: 573-7.

4. Vandenbroucke JP, von Elm E, Altman DG, For the STROBE Initiative, et al. Strengthening the Reporting of Observational Studies in Epidemiology (STROBE): explanation, elaboration. PLoS Med 2007; 4: e297.

5. Peduzzi P, Concato J, Kemper E, Holford TR, Feinstein AR. A simulation study of the number of events per variable in logistic regression analysis. J Clin Epidemiol 1996; 49: 1373-9.

6. Petersen MS, Collins DN, Selakovich WG, Finkbeiner AE. Postoperative urinary retention associated with total hip and total knee arthroplasties. Clin Orthop Relat Res 1991; 269: 102-8. 
7. Waterhouse N, Beaumont AR, Murray K, Staniforth P, Stone MH. Urinary retention after total hip replacement. A prospective study. J Bone Joint Surg Br 1987; 69: 64-6.

8. Sarasin SM, Walton MJ, Singh HP, Clark DI. Can a urinary tract symptom score predict the development of postoperative urinary retention in patients undergoing lower limb arthroplasty under spinal anaesthesia? A prospective study. Ann R Coll Surg Engl 2006; 88: 394-8.

9. Souron V, Delaunay L, Schifrine P. Intrathecal morphine provides better postoperative analgesia than psoas compartment block after primary hip arthroplasty. Can J Anesth 2003; 50: 574-9.

10. Hebl JR, Dilger JA, Byer DE, et al. A pre-emptive multimodal pathway featuring peripheral nerve block improves perioperative outcomes after major orthopedic surgery. Reg Anesth Pain Med 2008; 33: 510-7.

11. Kotwal $R$, Hodgson $P$, Carpenter $C$. Urinary retention following lower limb arthroplasty: analysis of predictive factors and review of literature. Acta Orthop Belg 2008; 74: 332-6.
12. Elkhodair S, Parmar HV, Vanwaeyenbergh J. The role of the IPSS (International Prostate Symptoms Score) in predicting acute retention of urine in patients undergoing major joint arthroplasty. Surgeon 2005; 3: 63-5.

13. Hansen BS, Søreide E, Warland AM, Nilsen $O B$. Risk factors of post-operative urinary retention in hospitalised patients. Acta Anaesthesiol Scand 2011; 55. doi:10.1111/j.1399-6576.2011. 02416.x

14. Iorio R, Healy WL, Patch DA, Appleby D. The role of bladder catheterization in total knee arthroplasty. Clin Orthop Relat Res 2000; 380: 80-4.

15. van den Brand IC, Castelein RM. Total joint arthroplasty and incidence of postoperative bacteriuria with an indwelling catheter or intermittent catheterization with one-dose antibiotic prophylaxis. J Arthroplasty 2001; 16: 850-5.

16. Iorio $R$, Whang $W$, Healy WL, Patch DA, Najibi S, Appleby D. The utility of bladder catheterization in total hip arthroplasty. Clin Orthop Relat Res 2005; 432: 148-52. 